\title{
Glutamatergic Neurons of the Mouse Medial Septum and Diagonal Band of Broca Synaptically Drive Hippocampal Pyramidal Cells: Relevance for Hippocampal Theta Rhythm
}

\author{
Carey Y. L. Huh, Romain Goutagny, and Sylvain Williams \\ Neuroscience Division, Douglas Mental Health University Institute, McGill University, Montréal, Québec H4H 1R3, Canada
}

\begin{abstract}
Neurons of the medial septum and diagonal band of Broca (MS-DBB) provide an important input to the hippocampus and are critically involved in learning and memory. Although cholinergic and GABAergic MS-DBB neurons are known to modulate hippocampal activity, the role of recently described glutamatergic MS-DBB neurons is unknown. Here, we examined the electrophysiological properties of glutamatergic MS-DBB neurons and tested whether they provide a functional synaptic input to the hippocampus. To visualize the glutamatergic neurons, we used MS-DBB slices from transgenic mice in which the green fluorescent protein is expressed specifically by vesicular glutamate transporter 2-positive neurons and characterized their properties using whole-cell patch-clamp technique. For assessing the function of the glutamatergic projection, we used an in vitro septohippocampal preparation, electrically stimulated the fornix or chemically activated the MS-DBB using NMDA microinfusions and recorded postsynaptic responses in CA3 pyramidal cells. We found that glutamatergic MS-DBB neurons as a population display a highly heterogeneous set of firing patterns including fast-, cluster-, burst-, and slow-firing. Remarkably, a significant proportion exhibited fast-firing properties, prominent $\mathrm{I}_{\mathrm{h}}$, and rhythmic spontaneous firing at theta frequencies similar to those found in GABAergic MS-DBB neurons. Activation of the MS-DBB led to fast, AMPA receptormediated glutamatergic responses in CA3 pyramidal cells. These results describe for the first time the electrophysiological signatures of glutamatergic MS-DBB neurons, their rhythmic firing properties, and their capacity to drive hippocampal principal neurons. Our findings suggest that the glutamatergic septohippocampal pathway may play an important role in hippocampal theta oscillations and relevant cognitive functions.
\end{abstract}

\section{Introduction}

The medial septum and diagonal band of Broca (MS-DBB) is mutually connected with the hippocampus and provides an important input for spatial learning and hippocampal theta rhythm (Winson, 1978). Cholinergic and GABAergic neurons are well known to exist in the MS-DBB, and their intrinsic properties have been described in detail. In slices, cholinergic MS-DBB neurons fire slowly, distinguished by broad action potentials and slow afterhyperpolarization (AHP) (Griffith and Matthews, 1986; Markram and Segal, 1990), whereas most GABAergic MS-DBB neurons display fast- or burst-firing properties and a large $\mathrm{I}_{\mathrm{h}}$, a hyperpolarization-activated inward current (Morris et al., 1999; Knapp et al., 2000). In vivo, cholinergic neurons discharge infrequently while GABAergic neurons produce rhythmic bursts phase locked to the ongoing hippocampal theta oscillations (Borhegyi et al., 2004; Simon et al., 2006). In terms of hippocampal projections, cholinergic neurons innervate both pyramidal cells

Received July 13, 2010; revised Sept. 13, 2010; accepted Sept. 24, 2010.

This work was supported by Natural Sciences and Engineering Research Council of Canada (NSERC), Canadian Institutes of Health Research. C.H. received a NSERC Canada Graduate Scholarship. S.W. is a recipient of a Fonds de la recherche en santé du Québec senior fellowship.

Correspondence should be addressed to Sylvain Williams, Department of Psychiatry, McGill University, Douglas Mental Health University Institute, 6875 Lasalle Boulevard, Montréal, Québec H4H 1R3, Canada. E-mail: wilsyl@ douglas.mcgill.ca.

DOI:10.1523/JNEUROSCI.3663-10.2010

Copyright $\odot 2010$ the authors $\quad 0270-6474 / 10 / 3015951-11 \$ 15.00 / 0$ and interneurons, likely providing long-lasting depolarizations (Cole and Nicoll, 1983; Widmer et al., 2006), whereas GABAergic neurons specifically target hippocampal interneurons, providing rhythmic inhibitory inputs that in turn disinhibit pyramidal cells (Freund and Antal, 1988; Toth et al., 1997).

Recently, using vesicular glutamate transporter 2 (VGLUT2) as a marker, a third population of neurons has been found in the MS-DBB that uses glutamate as a neurotransmitter (Lin et al., 2003; Sotty et al., 2003; Hajszan et al., 2004; Danik et al., 2005). This population is estimated to constitute $25 \%$ of the MS-DBB population (Colom et al., 2005) and to provide $4-23 \%$ of the septohippocampal projection (Colom et al., 2005; Henderson et al., 2010). Using electrophysiology and single-cell reverse transcriptase-PCR, VGLUT2-positive MS-DBB neurons have been shown to display slow- and cluster-firing properties in slices (Sotty et al., 2003), and glutamatergic MS-DBB neurons are mutually connected with local cholinergic and GABAergic neurons (Manseau et al., 2005). However, key questions remain as to whether the glutamatergic neurons can be distinguished from other MS-DBB neurons electrophysiologically, which hippocampal cell types they target, and the functional consequence of this projection. In addition, given that many MS-DBB neurons fire rhythmically in theta-range frequencies in vivo, it is unknown whether glutamatergic neurons participate in this rhythmic activity.

In this study, we aimed to characterize the intrinsic membrane properties of glutamatergic MS-DBB neurons and examine 
whether the glutamatergic septohippocampal pathway is functional. To address these questions, we used transgenic mice in which the expression of the VGLUT2 gene is linked with that of the enhanced green fluorescent protein (eGFP). VGLUT2 is considered a specific marker for glutamatergic neurons (Fremeau et al., 2001), and it is highly expressed in the rodent MS-DBB (Sotty et al., 2003; Danik et al., 2005). Second, we used an in vitro septohippocampal preparation where the fornix-fimbria fibers are kept intact to probe whether hippocampal cells receive glutamatergic synaptic input from MS-DBB neurons.

We demonstrate here that a subset of glutamatergic MS-DBB neurons are fast-firing neurons with spontaneous spiking in theta-range frequencies that is as rhythmic as that displayed by GABAergic MS-DBB neurons. We also present new evidence that glutamatergic MS-DBB neurons provide functional excitatory input to CA3 pyramidal cells.

\section{Materials and Methods}

Animals. Experiments were performed using VGLUT2-eGFP transgenic mice unless otherwise stated. VGLUT2-eGFP mice [strain name: STOCK $\mathrm{Tg}$ (Slc17a6-EGFP)FY115Gsat/Mmcd], developed under the Gene Expression Nervous System Atlas (GENSAT) project (Gong et al., 2003), were obtained from the Mutant Mouse Regional Resource Center (MMRRC). In these mice, the genotype was modified to contain multiple copies of a modified bacterial artificial chromosome (BAC) in which the eGFP reporter gene was inserted immediately upstream of the coding sequence of the targeted gene (VGLUT2). In experiments where GABAergic MS-DBB neurons were examined, another transgenic mouse line developed using the BAC technology was used, in which the eGFP was expressed under the control of the glutamic acid decarboxylase 65 gene (GAD65) [strain name: STOCK Tg(Gad2-EGFP)31Gsat/Mmcd]. For both transgenic mouse strains, the background was FVB/N-Swiss Webster hybrid, and heterozygotes were purchased from the MMRRC and mated with wild-type Swiss Webster (CFW) mice (Charles River). The transgene expression in the offspring was checked by illuminating the brain of live pups (1-2-d-old) using a GFP flashlight (NightSea). In some experiments noted, wild-type CFW mice were used. Animals were treated according to protocols and guidelines approved by McGill University and the Canadian Council of Animal Care.

Autaptic cultures. Cell cultures were prepared using MS-DBB cells from VGLUT2-eGFP or GAD65-eGFP transgenic mice according to previously described protocols (Huh et al., 2008) adapted from Bourque and Trudeau (2000) with some modifications. All drugs were obtained from Sigma unless otherwise noted. Astrocytic microislands were first established, and then MS-DBB neurons were cultured on the microislands. Briefly, glass coverslips were treated with poly-L-ornithine and agarose, and sprayed with liquid collagen (Cohesion Technology) using a microatomizer to create microislands permissive to cell growth. To obtain astrocytes, we extracted hippocampal tissue from 1-d-old mice and dissociated the tissue using papain (Worthington Biochemical). Cells were grown in flasks with media containing basal medium eagle, glucose, Mito + serum extender (Becton Dickinson Labware), penicillin/streptomycin (Invitrogen), GlutaMAX-1 (Invitrogen), and 5\% heat-inactivated fetal calf serum (Invitrogen). After $48 \mathrm{~h}$ of incubation $\left(37^{\circ} \mathrm{C} / 5 \% \mathrm{CO}_{2}\right)$, astrocytes were exposed to cold $\left(4^{\circ} \mathrm{C}\right)$ media and vigorous shaking to eliminate any surviving neurons and loosely attached cells. The remaining astrocytes were allowed to further proliferate, harvested and plated at 60,000 living cells $/ \mathrm{ml}$ on pretreated coverslips. 5-Fluoro-2' deoxyuridine (FDU) was added to inhibit further proliferation. Next, MS-DBB neurons were obtained from 11- to 14-d-old VGLUT2-eGFP or GAD65-eGFP mice, dissociated, and plated at 80,000 living cells $/ \mathrm{ml}$ on pre-established astrocytic microislands. The neurons were cultured in media containing astrocyteconditioned media, Neurobasal-A (Invitrogen), penicillin/streptomycin, GlutaMAX-1, B-27 (Invitrogen), and 5\% heat-inactivated fetal calf serum. Media were changed after $24 \mathrm{~h}$, at which point additional FDU was administered, and fresh media is added every seventh day. Recordings were performed on neurons cultured for 17-30 d.
Slice preparation. Brain slices containing the MS-DBB were obtained from 12- to 18-d-old VGLUT2-eGFP or GAD65-eGFP transgenic mice. Mice were killed by decapitation, and the brain was rapidly removed and placed in ice-cold high-sucrose solution containing the following (in mM): 252 sucrose, $24 \mathrm{NaHCO}_{3}, 10$ glucose, $3 \mathrm{KCl}, 2 \mathrm{MgCl}_{2}, 1.25$ $\mathrm{NaH}_{2} \mathrm{PO}_{4}$, and $1 \mathrm{CaCl}_{2}, \mathrm{pH} 7.3$ (oxygenated with $95 \% \mathrm{O}_{2} / 5 \% \mathrm{CO}_{2}$ ). Coronal slices of $300 \mu \mathrm{m}$ were cut using a vibrotome (Campden Instruments) and placed in a Petri dish containing artificial CSF (aCSF) containing the following (in mM): $126 \mathrm{NaCl}, 24 \mathrm{NaHCO}_{3}, 10$ glucose, $3 \mathrm{KCl}$, $2 \mathrm{MgCl}_{2}, 1.25 \mathrm{NaH}_{2} \mathrm{PO}_{4}$ and $1 \mathrm{CaCl}_{2}, \mathrm{pH} 7.3$ (oxygenated with $95 \%$ $\mathrm{O}_{2} / 5 \% \mathrm{CO}_{2}$ ) and left to equilibrate for $1 \mathrm{~h}$ at room temperature before recording.

Electrophysiology and eGFP labeling visualization. All electrophysiological recordings were performed at room temperature. Before recording, neurons were checked for the presence of soma eGFP labeling by illuminating with a 488-nm-wavelength light using a fluorescence system (PTI). The electrophysiology setup was equipped with an upright BX51W1 Olympus microscope, a $20 \times$ water-immersion objective, Nomarsky optics, an infrared camera (Cohu), a monochrome digital camera for fluorescence imaging (DAGE-MTI), and a custom-made submerged Plexiglas recording bath. Patch-pipettes (3-5 M $\Omega$ ) were pulled from borosilicate glass capillaries (Warner Instrument) and filled with intrapipette solution containing the following (in $\mathrm{mM}$ ): $144 \mathrm{~K}$-gluconate, 10 HEPES, $3 \mathrm{MgCl}_{2}, 2 \mathrm{Na}_{2} \mathrm{ATP}, 0.3 \mathrm{GTP}$, and $0.2 \mathrm{EGTA}$, adjusted to $\mathrm{pH} 7.2$ with $\mathrm{KOH}$. Neurons were recorded using visually guided whole-cell patch-clamp technique, an Axopatch-1C amplifier, and pClamp9 software (Molecular Devices). The junction potential estimated at $-14 \mathrm{mV}$ was not corrected.

For recording of autaptic neurons, we used an extracellular solution containing the following (in $\mathrm{mm}$ ): $140 \mathrm{NaCl}, 10$ glucose, 6 sucrose, $3 \mathrm{KCl}$, $2 \mathrm{CaCl}_{2}, 2 \mathrm{MgCl}_{2}, 10 \mathrm{HEPES}$, adjusted to $\mathrm{pH} 7.3$ with $\mathrm{NaOH}$, perfused at $1-2 \mathrm{ml} / \mathrm{min}$. Microislands were visually inspected to ensure that recordings were done on astrocytic islands that contained only one neuron. After an isolated fluorescent neuron was found (see Fig. $1 A$ ), the neuron was recorded in voltage-clamp to detect an autaptic current (see Fig. $1 B$ ). The current was considered to be an EPSC if its reversal potential was near $0 \mathrm{mV}$ and an IPSC if it reversed at a potential more negative than $-40 \mathrm{mV}$. We then determined the neurotransmitter released pharmacologically by bath applying 6,7-dinitroquinoxaline-2,3(1H,4H)-dione (DNQX) $(20 \mu \mathrm{M})$, tubocurarine $(10 \mu \mathrm{M})$, and/or bicuculline methiodide/chloride $(10 \mu \mathrm{M})$.

For electrophysiological characterization of MS-DBB neurons in slices, standard aCSF containing (in $\mathrm{mm}$ ) $126 \mathrm{NaCl}, 24 \mathrm{NaHCO}_{3}, 10$ glucose, $3 \mathrm{KCl}, 2 \mathrm{MgCl}_{2}, 1.25 \mathrm{NaH}_{2} \mathrm{PO}_{4}$, and $2 \mathrm{CaCl}_{2}$, $\mathrm{pH} 7.3$ (oxygenated with $95 \% \mathrm{O}_{2} / 5 \% \mathrm{CO}_{2}$ ), was perfused at $2-3 \mathrm{ml} / \mathrm{min}$. Properties examined include resting membrane potential (Vrest), spontaneous firing, firing pattern, mean firing rate, action potential and AHP parameters, sag amplitude, and kinetics. An approximate location of the recorded cell in the slice was also noted. Recordings were kept for analysis only if they met the stable recording criteria: spikes overshot $0 \mathrm{mV}$, spike amplitude exceeded $60 \mathrm{mV}$, access resistance was $<30 \mathrm{M} \Omega$, and Vrest and spontaneous firing rate fluctuated less than $\pm 10 \%$ for the duration of the cell's characterization. Intrinsic properties of each cell were examined in current-clamp mode following published protocols (Sotty et al., 2003). The membrane potential of the cell was held at $-80 \mathrm{mV}$, and a series of $1 \mathrm{~s}$ depolarizing current steps $(0-200 \mathrm{pA})$ was applied. The membrane was then held at $-60 \mathrm{mV}$, and sets of 1 and $5 \mathrm{~s}$ depolarizing currents were administered. Action potential and AHP parameters were measured from the voltage trace where the cell fired only one action potential from $-60 \mathrm{mV}$. Firing frequencies were determined from the trace where the neuron was depolarized from $-60 \mathrm{mV}$ using the same current step required to depolarize the cell to spike threshold from $-80 \mathrm{mV}$; the mean firing rate (in $\mathrm{Hz}$ ) was the number of spikes evoked by the $1 \mathrm{~s}$ depolarizing step; initial firing rate $\left(\mathrm{F}_{\text {INITIAL }}\right)$ was the neuron's firing frequency during the first $200 \mathrm{~ms}$; final firing rate $\left(\mathrm{F}_{\mathrm{FINAL}}\right)$ was that during the last $200 \mathrm{~ms}$; and spike accommodation (as percentage) was calculated as follows: $\left(\mathrm{F}_{\text {INITIAL }}-\mathrm{F}_{\text {FINAL }}\right) / \mathrm{F}_{\text {INITIAL }} \times 100$. When present, properties of the depolarizing sag were measured from $-50 \mathrm{mV}$ in response to the $1 \mathrm{~s}$ hyperpolarizing current step leading to an initial hyperpolarization to 
Table 1. Electrophysiological properties of VGLUT2-eGFP-(+) MS-DBB neurons in mouse coronal brain slices, total number of neurons recorded $=66$

\begin{tabular}{|c|c|c|c|c|c|}
\hline \multirow[b]{2}{*}{ Firing pattern } & \multirow[b]{2}{*}{ Cluster firing } & \multicolumn{2}{|l|}{ Fast firing } & \multirow[b]{2}{*}{ Burst firing } & \multirow[b]{2}{*}{ Slow firing } \\
\hline & & Large sag & No sag & & \\
\hline$N$ (\% of total number) & $13(19.7 \%)$ & $12(18.2 \%)$ & $19(28.8 \%)$ & $11(16.7 \%)$ & $11(16.7 \%)$ \\
\hline Vrest (mV) & $-53.0 \pm 1.6$ & $-50.3 \pm 1.0^{a}$ & $-51.5 \pm 1.3$ & $-52.0 \pm 0.9^{a}$ & $-49.5 \pm 1.0$ \\
\hline Proportion of spontaneous firing & $46.2 \%$ & $50.0 \%$ & $58.8 \%$ & $54.5 \%$ & $18.2 \%$ \\
\hline Mean frequency $(\mathrm{Hz})$ & $2.8 \pm 0.7$ & $3.7 \pm 1.3$ & $4.6 \pm 1.2$ & $2.5 \pm 0.6$ & $3.5 \pm 0.5$ \\
\hline Range (Hz) & $1-6$ & $1-9$ & $1-10$ & $1-5$ & $3-4$ \\
\hline Mean firing rate $(\mathrm{Hz})$ & $8.8 \pm 1.2^{b, c}$ & $15.8 \pm 1.6^{d, e, f}$ & $13.6 \pm 1.8^{d, e, f}$ & $9.1 \pm 0.9^{b, c}$ & $5.3 \pm 0.3^{b, c}$ \\
\hline $\mathrm{F}_{\text {INITIAL }}(\mathrm{Hz})$ & $12.7 \pm 2.2$ & $18.3 \pm 2.3^{f}$ & $15.8 \pm 1.9^{f}$ & $12.3 \pm 1.6$ & $5.9 \pm 0.6^{b, c}$ \\
\hline $\mathrm{F}_{\mathrm{FINAL}}(\mathrm{Hz})$ & $6.2 \pm 1.3^{b, c}$ & $15.4 \pm 2.1^{d, e, f}$ & $13.4 \pm 1.7^{d, e, f}$ & $7.7 \pm 1.0^{b, c}$ & $4.1 \pm 0.6^{b, c}$ \\
\hline Spike frequency accomodation (\%) & $51.8 \pm 10.4^{b, c}$ & $15.4 \pm 6.2^{d}$ & $13.4 \pm 3.8^{d}$ & $37.3 \pm 9.1$ & $27.3 \pm 12.4$ \\
\hline Spike threshold (mV) & $-41.2 \pm 0.9$ & $-43.1 \pm 1.0$ & $-44.1 \pm 1.2^{f}$ & $-43.9 \pm 1.3^{f}$ & $-38.9 \pm 1.1^{c, e}$ \\
\hline Spike amplitude (mV) & $78.1 \pm 2.9$ & $80.7 \pm 2.0$ & $79.8 \pm 2.2$ & $81.9 \pm 3.4$ & $76.6 \pm 2.2$ \\
\hline Spike half-width (ms) & $1.3 \pm 0.1$ & $1.3 \pm 0.1$ & $1.3 \pm 0.1$ & $1.2 \pm 0.1^{f}$ & $1.7 \pm 0.1^{e}$ \\
\hline AHP amplitude (mV) & $7.5 \pm 1.5$ & $5.9 \pm 0.9$ & $8.1 \pm 0.6$ & $4.9 \pm 0.6$ & $7.4 \pm 0.9$ \\
\hline AHP duration (ms) & $253.2 \pm 39.9$ & $262.8 \pm 31.4$ & $284.5 \pm 34.1$ & $292.6 \pm 20.8^{a}$ & $318.9 \pm 31.1$ \\
\hline Sag amplitude (mV) & $6.4 \pm 1.3^{b}$ & $16.1 \pm 1.4^{c, d, e, f}$ & $4.6 \pm 0.7^{b}$ & $3.2 \pm 1.1^{a, b}$ & $4.9 \pm 1.4^{b}$ \\
\hline Rebound spike delay (ms) & $124.5 \pm 42.6$ & $221.7 \pm 87.1$ & $94.2 \pm 18.4$ & $74.7 \pm 7.9$ & $74.3 \pm 6.1^{a}$ \\
\hline Sag activation time (ms) & - & $131.1 \pm 21.3$ & - & - & - \\
\hline Sag decay constant (ms) & - & $176.9 \pm 19.5$ & - & - & - \\
\hline Subthreshold oscillation frequency (Hz) & $17.8 \pm 2.4$ & - & - & - & - \\
\hline Intracluster/burst frequency (Hz) & $15.8 \pm 2.2$ & - & - & $58.6 \pm 11.4$ & - \\
\hline No. of spikes per cluster/burst & $4.9 \pm 0.6$ & - & - & $2.3 \pm 0.3$ & - \\
\hline LTS amplitude (mV) & - & - & - & $15.3 \pm 1.2^{a}$ & - \\
\hline LTS duration (ms) & - & - & - & $162.7 \pm 39.5$ & - \\
\hline
\end{tabular}

Values are given as mean \pm SE. Statistically significant differences $(p<0.05)$ are indicated as follows: ${ }^{a}$ versus GAD65-eGFP-(+) cells with a similar firing pattern ${ }^{b}$ versus fast-firing cells with large sag; ${ }^{c}$ versus fast-firing cells with no sag; ${ }^{d}$ versus cluster-firing cells; ${ }^{e}$ versus burst-firing cells; ${ }^{f}$ versus slow-firing cells.

$-120 \mathrm{mV} . \mathrm{ZD} 7288$ (50 $\mu \mathrm{m}$; Tocris Cookson) was used to block $\mathrm{I}_{\mathrm{h}}$ in some experiments. In the cases indicated, neurons were recorded in the presence of blockers of synaptic inputs: DNQX $(10 \mu \mathrm{M})$, bicuculline $(5 \mu \mathrm{M})$, tubocurarine $(5 \mu \mathrm{M}), \mathrm{AP}-5(25 \mu \mathrm{M})$, and atropine $(10 \mu \mathrm{M})$.

Neurons firing regularly with the mean firing rate of $\leq 7 \mathrm{~Hz}$ were classified as "slow-firing" cells, and those with higher firing rates were considered "fast-firing" cells. Neurons displaying clusters of action potentials and clear subthreshold oscillations were categorized as "cluster-firing" cells. "Burstfiring" neurons fired at least two spikes on top of a conspicuous lowthreshold spike (LTS) when depolarized from $-80 \mathrm{mV}$. Several additional properties were measured for burst- and cluster-firing neurons (Table 1; supplemental Table S1, available at www.jneurosci.org as supplemental material). Neurons displaying a depolarizing sag of $\geq 10 \mathrm{mV}$ when hyperpolarized to $-120 \mathrm{mV}$ were judged as having a "large sag," and kinetics of the depolarizing sag were measured only for these neurons. Sag decay constant was the time point at which the sag decayed to $50 \%$ of the initial amplitude.

The degree of rhythmicity in spontaneous firing was measured as follows. The cell was recorded at Vrest to check for the presence of spontaneous spiking for $30 \mathrm{~s}$, and then a current was injected to hold the cell at $-70 \mathrm{mV}$ for $30 \mathrm{~s}$ to reveal spontaneous synaptic events, before the cell was characterized for electrophysiological properties. For neurons that displayed $4-12 \mathrm{~Hz}$ spontaneous firing, an interspike interval (ISI) histogram and a spike autocorrelogram were constructed using Spike2 software (Cambridge Electronic Design). To quantify the rhythmicity of spontaneous firing, a "theta index" (adapted from Royer et al., 2010) was calculated based on the fitted curve of the autocorrelogram obtained using a moving average function (see Fig. $3 B$ ). Here, the theta index is defined as the ratio $a / b$ where $b$ is the total amplitude of the second peak of the autocorrelogram (rhythmic and noise portions), and $a$ is the amplitude of the rhythmic portion of the second peak (total amplitude - amplitude of trough).

Septohippocampal preparation. The acute preparation containing a hemiseptum, ipsilateral hippocampus and fornix-fimbria fibers were dissected as described previously (Manseau et al., 2008). For these experiments, wild-type CFW mice (12-18 d old) were used unless otherwise stated. After decapitation, the brain was quickly removed and placed in ice-cold high-sucrose solution (for composition, see Slice preparation above). From a hemisected brain, the septum and hippocampus along with the interconnecting fibers were carefully dissected out using a microspatula, and the CA3 surface was cut at a $45^{\circ}$ angle using a blade. Each septohippocampal preparation was left to rest in aCSF $(1 \mathrm{~mm}$
$\mathrm{CaCl}_{2}$ ) at room temperature for $1-2 \mathrm{~h}$ before recording. The preparation was oriented in the recording chamber as shown in Figure $4 A i$ to allow direct access of the recording pipette to the CA3 pyramidal layer and perfused with standard aCSF $\left(2 \mathrm{~mm} \mathrm{CaCl}_{2}\right)$ at $2-3 \mathrm{ml} / \mathrm{min}$. Hippocampal neurons were recorded using the same technique and recording criteria as for MS-DBB neurons.

For electrical stimulation experiments, a monopolar tungsten microelectrode (World Precision Instruments) was placed in the septal end of the fornix, and stimulation parameters were controlled by an isolated pulse stimulator (A-M Systems). One to three current pulses (400 $\mu \mathrm{A}$, $100 \mu$ s duration, separated by $20 \mathrm{~ms}$ ) were administered at $10 \mathrm{~s}$ intervals to detect evoked responses in CA3 pyramidal neurons. In some cases, single stimuli at different intensities $(25-400 \mu \mathrm{A})$ or multiple stimuli at various frequencies $(1-6 \mathrm{~Hz})$ were given.

Experiments with local NMDA microinfusions required the use of a puffer pipette (a patch-pipette gently broken at the tip to achieve resistance of $\sim 1 \mathrm{M} \Omega$ ) positioned with the tip touching the MS-DBB area in the septohippocampal preparation (see Fig. 5Ai). The puffer pipette was loaded with 20-30 $\mu$ l of NMDA dissolved in normal aCSF at a final concentration of 200 $\mu \mathrm{M}$ and controlled by a picospritzer system (Medical Systems). Single pulses or sets of three pressure pulses (10-30 psi, $100 \mathrm{~ms}$ duration, separated by 200 $\mathrm{ms}$ ) were applied at $20 \mathrm{~s}$ intervals to examine responses in nearby MS-DBB neurons or in CA3 pyramidal cells. A maximum of 30 NMDA puffs were applied in each preparation to minimize toxicity and physical damage. For both fornix stimulation and NMDA infusion experiments, a minimum of three responses was averaged to calculate the mean amplitude and latency of the response for each cell, and DNQX $(20 \mu \mathrm{M})$ or bicuculline $(5 \mu \mathrm{M})$ was applied to identify the neurotransmitter involved.

Statistical analysis. Data are presented as mean \pm SEM, unless otherwise stated. Electrophysiological data were analyzed and plotted using Spike2 and Prism 4 (GraphPad Software). Statistical methods used were Student's $t$ test, ANOVA and post hoc Newman-Keuls tests. $p$ values of $<0.05$ were considered to be statistically significant.

\section{Results}

VGLUT2-eGFP-(+) MS-DBB neurons functionally release glutamate

Before using VGLUT2-eGFP transgenic mice as a tool to visualize glutamatergic neurons of the MS-DBB, we performed a control 
A

$$
\text { VGLUT2-eGFP-(+) }
$$

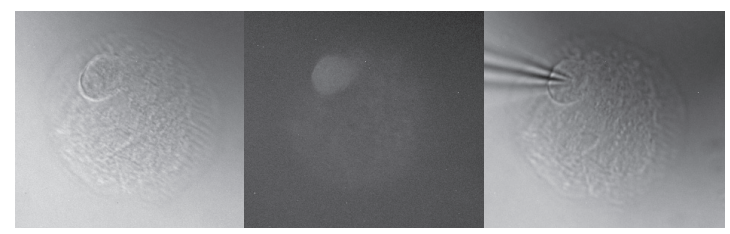

B

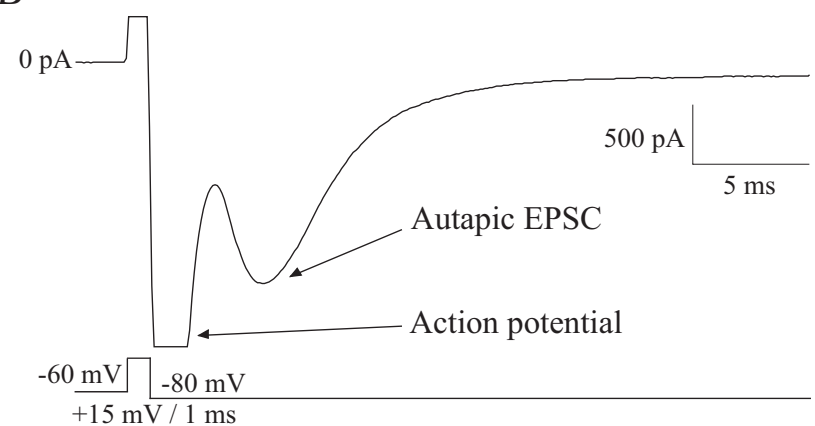

C

$$
\text { control }
$$

DNQX

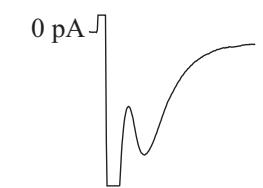

$-60 \mathrm{mV} \leftrightharpoons$

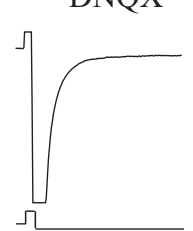

wash overlay
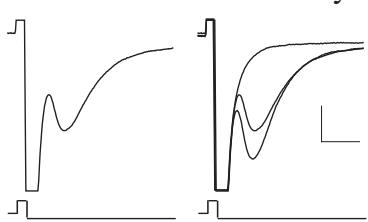

Figure 1. VGLUT2-eGFP-(+) MS-DBB neurons functionally release glutamate. $A$, An isolated fluorescent MS-DBB neuron cultured from VGLUT2-eGFP transgenic mice. $B$, Autaptic neurons were held in voltage-clamp and stimulated to fire an action potential, resulting in neurotransmitter release and postsynaptic autaptic currents. An example of an autaptic EPSC displayed by a VGLUT2-eGFP-(+) MS-DBB neuron is shown. C, A typical VGLUT2-eGFP- $(+)$ cell exhibited an EPSC that was completely and reversibly blocked by $20 \mu \mathrm{m} \mathrm{DNQX}$, indicating that the neuron released glutamate. Scale bars, $500 \mathrm{pA}, 5 \mathrm{~ms}$.

experiment to verify that the eGFP expression in these mice did not compromise the ability of cells to release glutamate and to ensure that the eGFP was expressed solely by glutamatergic neurons. Specifically, we aimed to confirm that the VGLUT2-eGFP(+) MS-DBB cells can functionally release glutamate. To this end, we established microisland cultures using MS-DBB neurons from VGLUT2-eGFP transgenic mice, allowing the isolated neurons to form autaptic connections over time, and determined the neurotransmitter(s) released by each neuron using pharmacology. Figure $1 A$ shows an example of an isolated MS-DBB neuron that expressed VGLUT2-eGFP. Autaptic currents were recorded by holding the neuron in voltage-clamp at $-60 \mathrm{mV}$, depolarizing it to $+15 \mathrm{mV}$ for $1 \mathrm{~ms}$ to evoke an action potential, then holding the neuron at $-80 \mathrm{mV}$ for $150 \mathrm{~ms}$ to reveal the postsynaptic autaptic current (Fig. $1 B$ ), and this protocol was repeated every $60 \mathrm{~s}$. Once a stable baseline for the current was obtained, drugs were applied to block currents mediated by AMPA/kainate receptors (DNQX), nicotinic receptors (tubocurarine), or $\mathrm{GABA}_{\mathrm{A}}$ receptors (bicuculline) to determine the neurotransmitter released.

We found that of 11 VGLUT2-eGFP-(+) MS-DBB neurons characterized, all 11 cells exhibited autaptic EPSCs that were completely blocked by $20 \mu \mathrm{M}$ DNQX (control: $-756.3 \pm 293.3$ pA; DNQX: $-101.2 \pm 17.03 \mathrm{pA})$. Figure $1 C$ shows a typical example of a VGLUT2-eGFP- $(+)$ neuron that displayed an autaptic EPSC that was completely and reversibly blocked by DNQX. In some neurons, the autaptic currents were further tested with
$10 \mu \mathrm{M}$ tubocurarine or $10 \mu \mathrm{M}$ bicuculline, and we found that the autaptic currents were not further reduced by these drugs (DNQX and tubocurarine: 5 cells, $96.7 \pm 2.3 \%$ normalized to DNQX effect size; DNQX and bicuculline: 4 cells, $99.5 \pm 0.4 \%$; data not shown), confirming that the only neurotransmitter released by these neurons is glutamate. These results demonstrate that VGLUT2-eGFP- $(+)$ MS-DBB neurons can functionally release glutamate. In a separate set of experiments, similar characterizations were performed on MS-DBB neurons from GAD65-eGFP transgenic mice, and we found that GAD65eGFP-(+) MS-DBB neurons can functionally release GABA (8 of 8 neurons; autaptic IPSCs in control: $-194.0 \pm 41.8 \mathrm{pA}$; bicuculline: $-41.3 \pm 11.2 \mathrm{pA}$ ) (supplemental Fig. S1, available at www. jneurosci.org as supplemental material).

\section{Electrophysiological characteristics of glutamatergic MS-DBB neurons}

We next investigated the electrophysiological properties of glutamatergic MS-DBB neurons in slices and examined whether they could be differentiated from GABAergic neurons. A previous study using rat slices reported that MS-DBB neurons expressing VGLUT2 transcripts display various firing patterns including cluster firing and slow firing (Sotty et al., 2003), but a comprehensive analysis of the electrophysiological characteristics of glutamatergic MS-DBB neurons has not been done. By using VGLUT2-eGFP transgenic mice, we were able to visually select fluorescent glutamatergic MS-DBB neurons (Fig. 2A) and record specifically from these neurons. Electrophysiological characterization was performed in current-clamp mode, and the properties examined included Vrest, spontaneous firing at rest, firing pattern upon depolarization, action potential properties, and presence of a depolarizing sag upon hyperpolarization. For comparison, similar characterizations were performed on GABAergic MS-DBB neurons using brain slices from GAD65-eGFP transgenic mice, and their electrophysiological properties are summarized in supplemental Table S1 and supplemental Figure S2 (available at www.jneurosci.org as supplemental material).

We found that glutamatergic MS-DBB neurons display a wide range of firing patterns that include cluster, fast, burst, and slow firing (Table 1, Fig. 2). Cluster-firing cells (13 of 66 cells) were unique in their tendency to fire clusters of action potentials when subjected to long $5 \mathrm{~s}$ depolarizations (Fig. $2 \mathrm{C}$, right), and the clusters were interspersed with subthreshold membrane oscillations (Fig. $2 C$, right inset). Importantly, cluster firing was only observed among VGLUT2-eGFP- $(+)$ cells and not GAD65eGFP- $(+)$ cells $(0 / 35)$ in response to the $5 \mathrm{~s}$ depolarizations. Cluster-firing cells were mostly silent or showed little spontaneous firing at rest and when depolarized they displayed a low mean firing rate $(8.8 \pm 1.2 \mathrm{~Hz})$ and large frequency accommodation (52 $\pm 10 \%)$. Upon hyperpolarization, most cluster-firing cells (9/13) showed little or no depolarizing sag (Fig. 2C, left). Clusterfiring neurons were located in lateral parts of the MS-DBB, avoiding the midline (Fig. $2 B$ ).

The largest proportion of glutamatergic MS-DBB neurons was fast firing (31/66). More than half of fast-firing cells were spontaneously active with firing frequencies between 1 and 10 Hz. Upon depolarization, fast-firing cells displayed a regular, tonic firing pattern (Fig. $2 D, E$ ) and a significantly higher mean firing rate $(14.5 \pm 1.3 \mathrm{~Hz})$ than cluster-, burst-, or slow-firing cells (all $p<0.05$ ). During the $1 \mathrm{~s}$ depolarizing step, fast-firing cells showed the least amount of frequency accommodation $(14 \pm 4 \%)$, and their $\mathrm{F}_{\mathrm{FINAL}}$ was significantly higher than all other cell types (all $p<0.05$ ). In response to hyperpolarization, some 
A

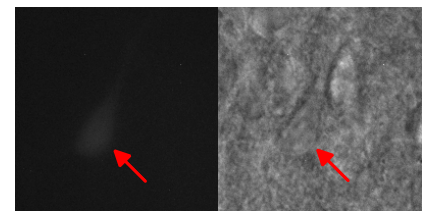

B

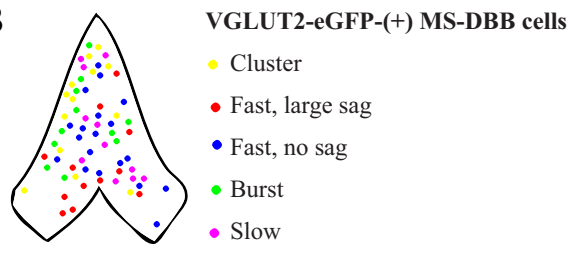

$\mathrm{C}$

Cluster (13)
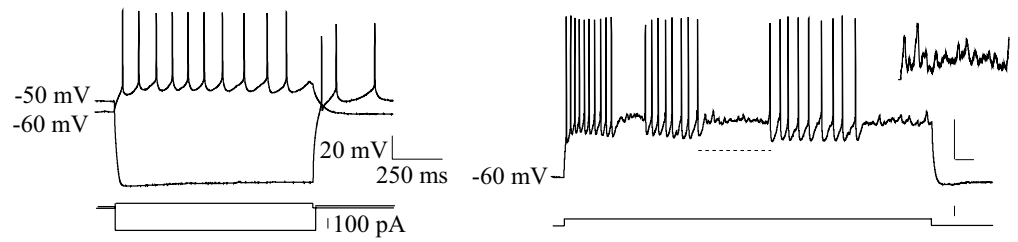

$\mathrm{D}$ Fast, large sag (12)
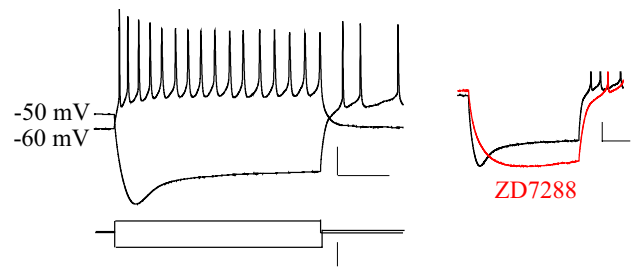

$\mathrm{F}$

Burst (11)

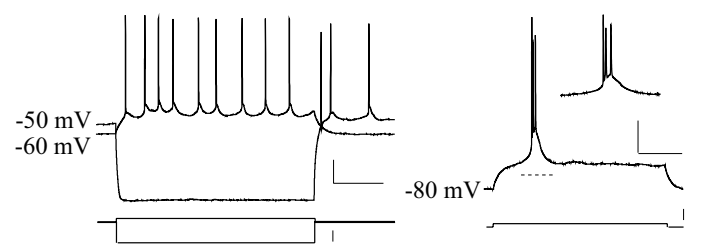

E Fast, no sag (19)

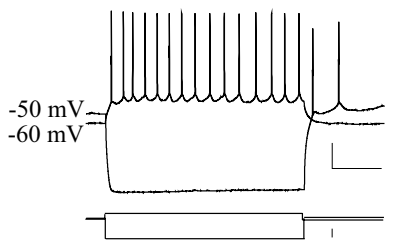

G

Slow (11)

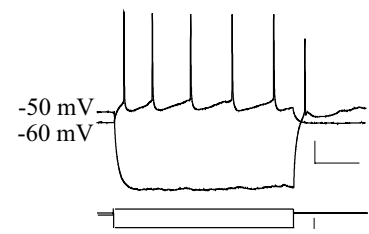

Figure 2. Electrophysiological characteristics of glutamatergic MS-DBB neurons. A, A VGLUT2-eGFP-(+) MS-DBB neuron (soma indicated by an arrow) in an acute slice. $\boldsymbol{B}$, Approximate locations of recorded VGLUT2-eGFP- $(+$ ) neurons in the MS-DBB are indicated, color coded by firing pattern; cluster- and burst-firing glutamatergic neurons were found in lateral regions of the MS-DBB, fast-firing cells were located more medially, slow-firing neurons were found in all MS-DBB subregions. C, Cluster-firing glutamatergic neurons displayed clusters of spikes observable during 5 s depolarizing steps (right), interspersed with subthreshold oscillations (right, inset). $D$, Upon hyperpolarization, some fast-firing glutamatergic neurons showed a prominent depolarizing sag that was completely blocked by $50 \mu \mathrm{m}$ ZD7288 (inset). $\boldsymbol{E}$, Other fast-firing neurons possessed little or no sag. $\boldsymbol{F}$, Burst-firing glutamatergic neurons presented bursts of several action potentials when depolarized from $-80 \mathrm{mV}$ (right) but fired regularly from $-60 \mathrm{mV}$ (left). G, Slow-firing glutamatergic neurons fired in a tonic manner at a low rate and typically showed little sag. Numbers in brackets indicate number of cells. Calibration: $20 \mathrm{mV}, 250 \mathrm{~ms}$ (voltage traces), $100 \mathrm{pA}$ (current steps).

fast-firing cells displayed a prominent depolarizing sag $(12 / 31)$ (Fig. 2D), while other fast-firing cells showed little or no sag (19/31) (Fig. 2E). The amplitude of sag displayed by the fastfiring, large-sag group was larger than that displayed by all other cell types. To determine whether the depolarizing sag is due to $I_{h}$, a hyperpolarization-activated current that has been associated with GABAergic MS-DBB neurons (Morris et al., 2004), the specific $\mathrm{I}_{\mathrm{h}}$ blocker ZD7288 was applied. ZD7288 (50 $\left.\mu \mathrm{M}\right)$ abolished the depolarizing sag in all the glutamatergic cells tested (4/4) (Fig. $2 D$, inset), demonstrating that some fast-firing glutamatergic MS-DBB neurons possess significant $\mathrm{I}_{\mathrm{h}}$. Interestingly, a proportion of GAD65-eGFP-(+) MS-DBB cells also exhibited the two types of fast firing, with some neurons possessing large sag and others showing little or no sag (supplemental Fig. S2C,D, available at www.jneurosci.org as supplemental material). Fast-firing glutamatergic neurons and fast-firing GABAergic neurons were not significantly different in any of the electrophysiological properties tested, except for Vrest (GABAergic cells were more depolarized at rest; see Table 1; supplemental Table S1, available at www.jneurosci.org as supplemental material). The amplitude and kinetics of the depolarizing sag were not significantly different between glutamatergic versus GABAergic neurons $(p>$ $0.05)$. Fast-firing glutamatergic neurons were located in all parts of the MS-DBB with the greatest concentration near the midline (Fig. $2 B$ ). The relative locations of fast-firing GABAergic MS-DBB neurons were similar (supplemental Fig. S2 B, available at www.jneurosci.org as supplemental material).

The third firing pattern displayed by glutamatergic MS-DBB neurons was burst firing (11/66). Burst-firing cells were characterized by firing of several action potentials together on top of a noticeable depolarizing hump (LTS) when released from a hyperpolarized potential of $-80 \mathrm{mV}$ (Fig. $2 \mathrm{~F}$, right) but firing regularly when depolarized from $-60 \mathrm{mV}$ (Fig. $2 F$, left). Burst-firing glutamatergic neurons were mostly quiescent or firing very little at rest. When depolarized, they displayed a relatively low mean firing rate $(9.1 \pm 0.9 \mathrm{~Hz})$ and moderate frequency accommodation $(37 \pm 9 \%)$. All burstfiring glutamatergic neurons expressed little or no sag upon hyperpolarization, a characteristic clearly distinct from burstfiring GABAergic neurons that showed significantly larger depolarizing sag $(p<$ 0.05) (supplemental Fig. S2 E, left, available at www.jneurosci.org as supplemental material). Other parameters that differed between burst-firing glutamatergic and GABAergic neurons were Vrest, AHP duration, LTS amplitude ( $p$ values $<0.05$ ), and LTS duration (marginally significant; $p=0.06$ ) (Table 1 ; supplemental Table S1, available at www. jneurosci.org as supplemental material). Interestingly, burst-firing glutamatergic MS-DBB neurons were located in the lateral regions similar to cluster-firing cells (Fig. 2B), whereas burst-firing GABAergic MS-DBB neurons were predominantly located close to the midline (supplemental Fig. S2 B, available at www.jneurosci.org as supplemental material).

Last, some glutamatergic MS-DBB neurons displayed slowfiring properties (11/66). Almost all slow-firing neurons (9/11) were silent at rest. When depolarized, they fired regularly at a low rate $(5.3 \pm 0.3 \mathrm{~Hz})$ with some frequency accommodation $(27 \pm$ 12\%) (Fig. 2G). Slow-firing glutamatergic neurons displayed wider action potentials (greater spike half-width) than other glutamatergic cell types, but the difference was found to be statistically significant only with burst-firing glutamatergic neurons $(p<0.05)$. When hyperpolarized, most slow-firing cells $(10 / 11)$ displayed little or no sag. Slow-firing was also observed in a subset of GABAergic MS-DBB neurons (supplemental Fig. $\mathrm{S} 2 F$, available at www.jneurosci.org as supplemental material), and the two slow-firing groups were electrophysiologically similar. Slow-firing neurons were found in all subregions 
of the MS-DBB for both glutamatergic and GABAergic neurons (Fig. $2 B$; supplemental Fig. S2 $B$, available at www. jneurosci.org as supplemental material).

These results demonstrate that glutamatergic MS-DBB neurons display a highly heterogeneous set of firing patterns. Cluster firing is unique to glutamatergic neurons, but fast-firing glutamatergic neurons are electrophysiologically virtually identical to fast-firing GABAergic neurons. Burst- and slow-firing glutamatergic neurons also share many similarities with their GABAergic counterparts.

\section{Rhythmic spontaneous firing of glutamatergic MS-DBB neurons}

Given that some glutamatergic MS-DBB neurons show fastfiring characteristics and a prominent $\mathrm{I}_{\mathrm{h}}$, and are spontaneously active, we next examined whether such glutamatergic MS-DBB neurons have the intrinsic capacity to fire rhythmically in thetarange frequencies at rest. Such rhythmic properties are important to investigate since they could contribute to the "theta rhythm generator" capacity traditionally attributed to the MS-DBB (Buzsáki, 2002). Previous studies using rat slices have reported that neurochemically unidentified fast-firing MS-DBB neurons are often spontaneously active (Morris et al., 1999; Henderson et al., 2001), but the rhythmic nature of the spontaneous firing has not been examined. Our aim was to compare the rhythmic firing properties of spontaneously active fast-firing glutamatergic versus GABAergic neurons. To this end, we examined the spontaneous firing at the resting membrane potential acquired at the start of recording of each cell. If the cell displayed stable spontaneous firing at $4-12 \mathrm{~Hz}$ (for criteria of stable recordings, see Materials and Methods), the voltage trace containing the spontaneous spikes was further analyzed to construct an ISI histogram and an autocorrelogram. From the autocorrelogram, the theta index, which is a measure of how regularly and rhythmically a cell's spontaneous spikes occurred and gives values between 0 (arrhythmic) and 1 (rhythmic), was calculated (Fig. 3B). It was also verified whether these spontaneously active neurons were driven by synaptic inputs by examining synaptic potentials at $-70 \mathrm{mV}$.

We found that $21 \%$ of the fast-firing glutamatergic MS-DBB neurons recorded (6/29) fired spontaneously at $4-12 \mathrm{~Hz}$. The remaining fast-firing MS-DBB neurons showed little $(<4 \mathrm{~Hz})$ or no spontaneous firing. Among the fast-firing glutamatergic cells that fired spontaneously at theta frequencies, the mean spontaneous firing rate was $8.6 \pm 0.6 \mathrm{~Hz}$ and the theta index varied between 0.56 and 1 (mean: $0.84 \pm 0.07$ ). When held at $-70 \mathrm{mV}$, spontaneous synaptic potentials could be detected in some cells, but these events were infrequent $(0-3 \mathrm{~Hz})$ and nonrhythmic, indicating that the rhythmic spontaneous firing is probably an intrinsic property and not a result of rhythmic extrinsic input. Figure $3 A i$ shows a fast-firing glutamatergic MS-DBB neuron that displayed highly rhythmic spontaneous firing that was maintained for at least $30 \mathrm{~s}$ at Vrest of $-50 \mathrm{mV}$, but the cell revealed very little synaptic activity at $-70 \mathrm{mV}$. Notably, the interval between the spikes remained exceptionally uniform throughout the recording, leading to well defined clear peaks in the autocorrelogram (theta index of 1) (Fig. 3Aii). Supplemental Fig. S3Ai (available at www.jneurosci.org as supplemental material) illustrates an example of another fast-firing glutamatergic MS-DBB cell that fired less rhythmically, indicated by broader peaks in the autocorrelogram and theta index of 0.68 .

As for the GABAergic MS-DBB neurons, $75 \%$ of fast-firing GABAergic neurons recorded (18/24) fired spontaneously in
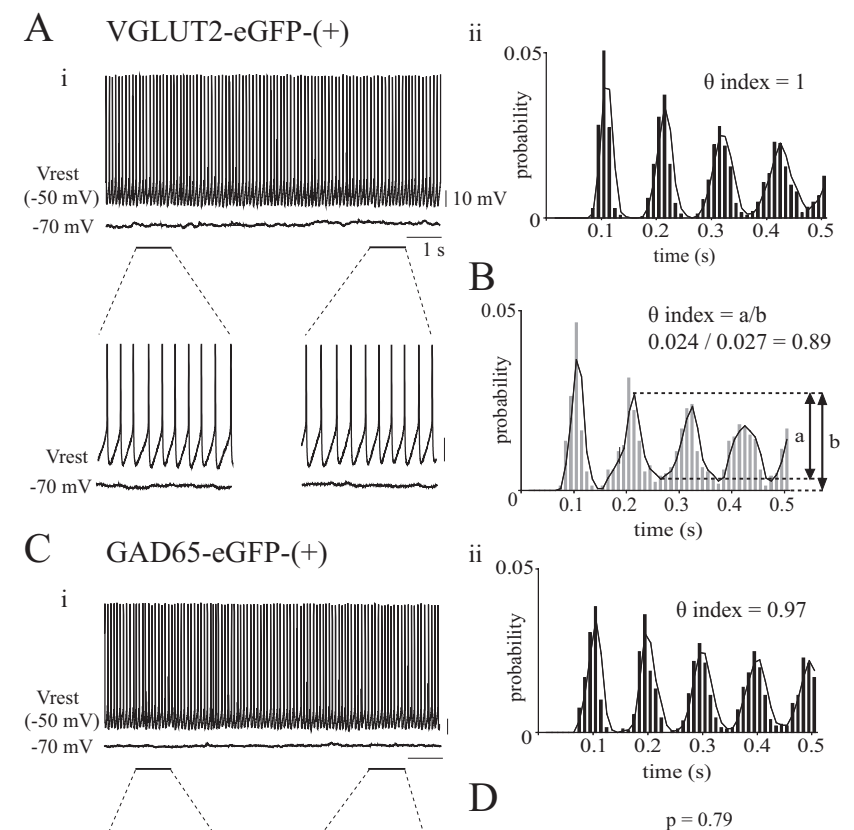

$\mathrm{D}$
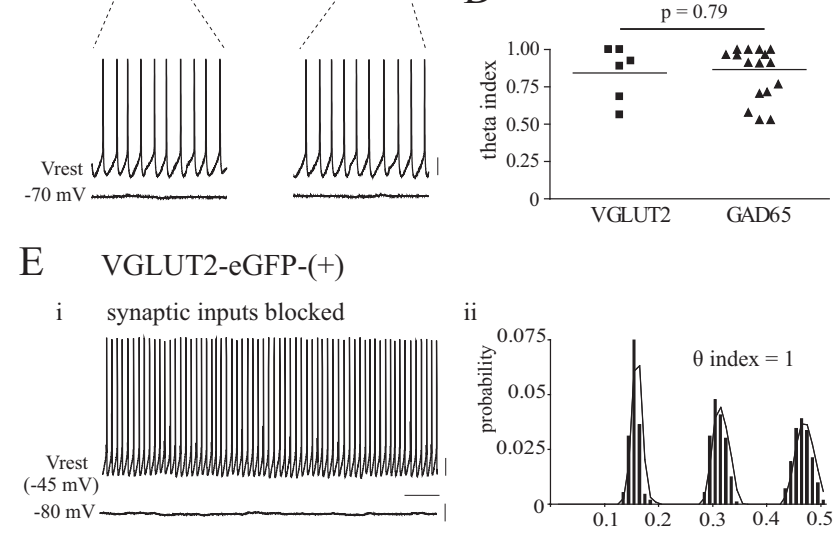

Figure 3. Rhythmic spontaneous firing of glutamatergic and GABAergic MS-DBB neurons. $A \boldsymbol{A}$, A subset of fast-firing glutamatergic MS-DBB neurons displayed highly rhythmic spontaneous firing in theta frequencies that was not driven by rhythmic extrinsic input (top: raw continuous voltage traces for 10 s at Vrest and at $-70 \mathrm{mV}$; bottom: two 1 s segments enlarged to show the extremely regular spontaneous firing and the lack of rhythmic synaptic input). Aii, The autocorrelogram of the spontaneous spikes recorded for $30 \mathrm{~s}$ with the theta index value indicated. Notice the clearly defined peaks and the high theta index value, indicating highly rhythmic spontaneous firing. $\boldsymbol{B}$, The theta index was calculated from the autocorrelogram, defined as the ratio $a / b$ where $b$ is the amplitude of the second peak and $a$ is the amplitude of the rhythmic portion of the second peak. Ci, Cii, Some fast-firing GABAergic MS-DBB neurons also showed highly rhythmic spontaneous firing. D, A scatterplot of theta index values for glutamatergic and GABAergic MS-DBB neurons shows that the degree of rhythmicity in spontaneous firing was not significantly different between the two groups. Ei, Eii, Glutamatergic MS-DBB neurons showed highly rhythmic spontaneous firing in the presence of blockers for synaptic inputs (10 $\mu \mathrm{m}$ DNQX, $5 \mu \mathrm{m}$ bicuculline, $5 \mu \mathrm{m}$ tubocurarine, $25 \mu \mathrm{m}$ AP-5, $10 \mu \mathrm{m}$ atropine). Calibration: $10 \mathrm{mV}, 1 \mathrm{~s}$.

theta-range frequencies. The mean spontaneous firing rate among these cells was $6.3 \pm 0.5 \mathrm{~Hz}$, and the mean theta index was $0.87 \pm 0.04$ (for examples of GABAergic cells' spontaneous firing, see Fig. 3C; supplemental Fig. S3B, available at www.jneurosci. org as supplemental material). Theta index values were not significantly different between glutamatergic and GABAergic neurons $(p=0.79)$ (Fig. $3 D)$, illustrating that the degree of rhythmicity in spontaneous firing was similar between glutamatergic and GABAergic neurons. These results suggest that both glutamatergic and GABAergic MS-DBB neurons fire rhythmically at rest but more GABAergic neurons exhibit this property. In all cases, spontaneous firing was in the form of repetitive single 
spikes and rhythmic burst-firing was not observed at rest in glutamatergic or GABAergic cells, consistent with other in vitro studies (Griffith, 1988; Henderson et al., 2001).

To demonstrate that the rhythmic spontaneous firing is an intrinsic property, we recorded from glutamatergic and GABAergic MS-DBB cells in the presence of blockers for both excitatory and inhibitory synaptic inputs (10 $\mu \mathrm{M}$ DNQX, $5 \mu \mathrm{M}$ bicuculline, $5 \mu \mathrm{M}$ tubocurarine, $25 \mu \mathrm{M}$ AP- $5,10 \mu \mathrm{M}$ atropine). Of five fastfiring glutamatergic neurons tested, two exhibited spontaneous firing in theta frequencies $(6.5$ and $5.6 \mathrm{~Hz})$ that was highly rhythmic (theta index of 1 and 0.98 , respectively). Figure $3 E$ shows the rhythmic spontaneous spikes and the lack of synaptic potentials displayed by one of the glutamatergic neurons in the presence of the blockers and the resulting autocorrelogram. As for GABAergic neurons, four of five fast-firing cells displayed spontaneous firing in the theta range $(4.6-11.4 \mathrm{~Hz})$ with varying degrees of rhythmicity (theta index of $0.56-1$ ) in the presence of the blockers. Two of these GABAergic neurons exhibited highly rhythmic spontaneous spikes (theta index of 1 and 0.94; data not shown).

Altogether, these results demonstrate that a subset of fastfiring glutamatergic MS-DBB neurons exhibit intrinsic spontaneous firing in theta-range frequencies that is as rhythmic as that displayed by fast-firing GABAergic cells, suggesting that they may be able to provide rhythmic excitatory input locally and potentially contribute to hippocampal oscillations.

\section{Functional glutamatergic septohippocampal projection}

We next investigated whether glutamatergic MS-DBB neurons send functional projections to the hippocampus. Anatomical studies have estimated that $4-23 \%$ of the septohippocampal projection is glutamatergic (Colom et al., 2005; Henderson et al., 2010). While cholinergic and GABAergic septohippocampal projections have been well described, no study has yet demonstrated the functional significance of the glutamatergic projection. To this aim, we used a septohippocampal preparation where a halfseptum, the ipsilateral hippocampus and the interconnecting fornix-fimbria fibers are preserved in an in vitro preparation. A previous study used a comparable in vitro preparation where a thick slice contained both the septum and the hippocampus (Toth et al., 1997), but the experiments were performed in the presence of blockers for glutamatergic receptors. The septohippocampal preparation used here has been used previously to study septohippocampal interactions (Goutagny et al., 2008; Manseau et al., 2008). As shown in Figure 4Ai, the preparation was positioned in the recording chamber with the CA3 side of the hippocampus facing up. The surface of the hippocampus was cut at an angle to expose the pyramidal layer of CA3. An electrode was placed on the septal side of the fornix bundle to electrically stimulate septohippocampal fibers, and postsynaptic responses were examined in CA3 pyramidal cells (Fig. 4Ai). Pyramidal cells were identified visually by the location of their soma in the pyramidal layer (Fig. 4 Aiii) and electrophysiologically by their slow-firing tendencies (Fig. 4Aii). For analysis, only the recordings from those preparations where septohippocampal connections were demonstrated to be intact (i.e., preparations where at least one CA3 cell showed a response to fornix stimulation) were included.

In 62 CA3 pyramidal cells analyzed, electrical stimulation of the fornix (400 $\mu \mathrm{A}, 100 \mu \mathrm{s}$ duration) led to consistent timelocked postsynaptic responses in 46 cells. No clear response was observed in the remaining 16 cells. Among the 46 cells with a response, at the holding potential of $-45 \mathrm{mV}, 34$ cells displayed a

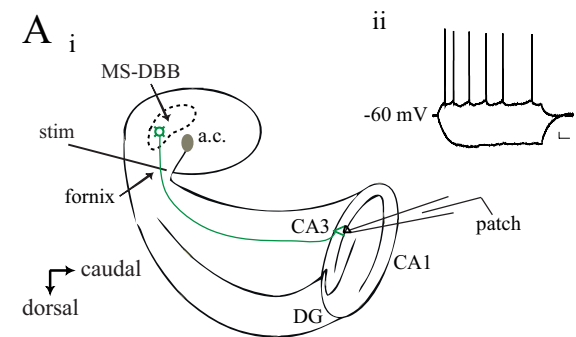

iii
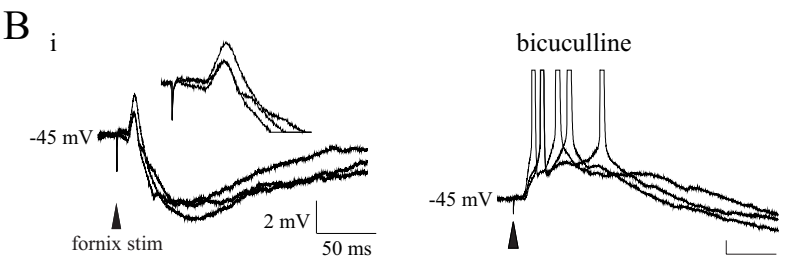

ii

bicuculline

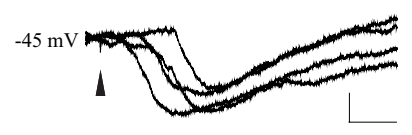

C control bicuculline
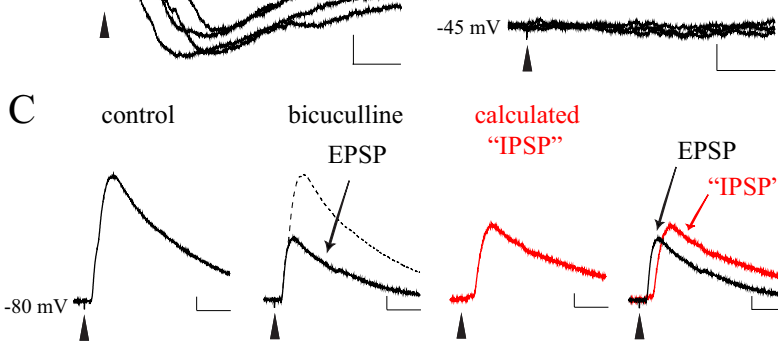
EPSP

calculated

"IPSP" EPSP

D
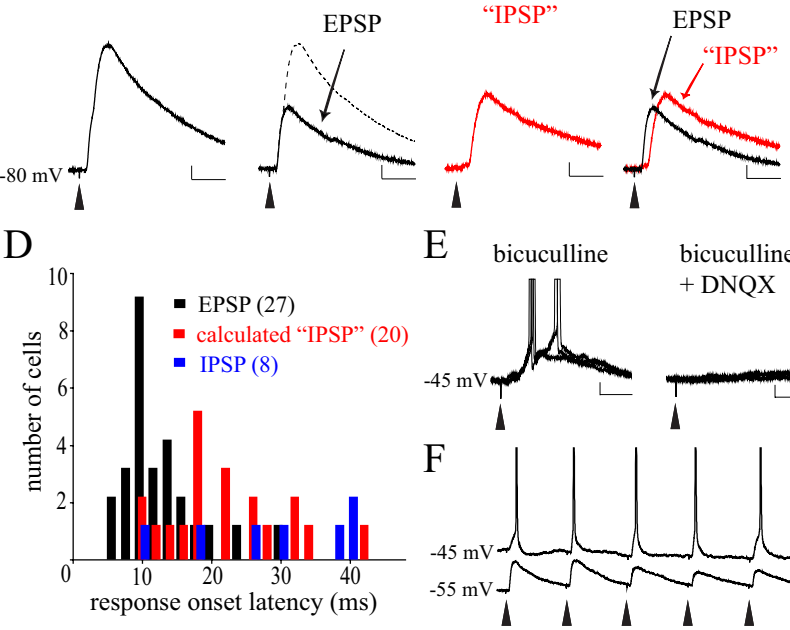

E bicuculline

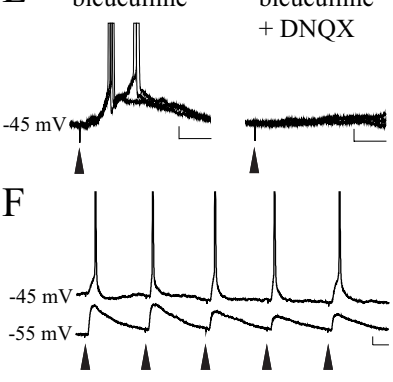

Figure 4. Electrical stimulation of septohippocampal fibers induced fast-onset glutamatergic responses in CA3 pyramidal cells. Ai, The septohippocampal preparation containing a hemiseptum, ipsilateral hippocampus, and intact fornix-fimbria pathway was cut at an angle to reveal the CA3 pyramidal layer and placed in the recording chamber as shown. A stimulating electrode was positioned on the septal side of the fornix and $C A 3$ pyramidal cells were recorded using a patch pipette. Aii, Aiii, CA3 pyramidal cells were identified by their location (Aiii) and electrophysiological criteria (Aii) (calibration: $20 \mathrm{mV}, 250 \mathrm{~ms}$ ). Bi, At $-45 \mathrm{mV}$, in most cases fornixstimulation led to both an early-onset EPSP (inset) and a late-onset IPSP. Applying bicuculline (5 $\mu \mathrm{m}$ ) revealed a potent EPSP that could depolarize some pyramidal cells to spike threshold (right). Bii, Some pyramidal cells responded with only the late-onset IPSP that was blocked by bicuculline. $C$, In those cells displaying both EPSP and IPSP, bicuculline was applied to isolate the EPSP and this component was subtracted from control to calculate the "IPSP" component. D, Examination of the onset latencies for EPSPS, calculated IPSPS, versus actual IPSPs indicates that the EPSPs occurred with a significantly faster onset compared with the other responses $(p<0.0001)$. Numbers in brackets indicate number of cells. $\boldsymbol{E}, \boldsymbol{F}$, The EPSP was mediated by glutamate as it was completely blocked by 20 $\mu \mathrm{M}$ DNQX $(\boldsymbol{E})$, and repeated stimuli at $5 \mathrm{~Hz}$ could evoke rhythmic EPSPs $(\boldsymbol{F})$. Calibration, unless otherwise noted: $2 \mathrm{mV}, 50 \mathrm{~ms}$. a.c., Anterior commissure.

mixture of EPSP and IPSP (Fig. 4Bi), 11 cells showed only IPSP (mediated by GABA release, see Fig. 4 Bii) and 1 cell showed only EPSP. Figure $4 B i$ illustrates an example of a CA3 pyramidal cell that displayed both EPSP and IPSP. Fornix stimulation led to an early-onset EPSP followed by a late-onset IPSP, and the different timing and direction of these two responses were clearly visible at $-45 \mathrm{mV}$ (EPSP: early/depolarizing, IPSP: late/hyperpolarizing). 
For those cells displaying both EPSP and IPSP, $5 \mu \mathrm{M}$ bicuculline was applied to block the IPSP and reveal the EPSP more clearly (Fig. 4 Bi, right). In the presence of bicuculline, the EPSP triggered action potentials from $-45 \mathrm{mV}$ in 17 of 34 pyramidal cells tested. When stimulation of various intensities were tested (25-400 $\mu \mathrm{A})$, we found that stronger stimuli led to systematically larger EPSPs in 14 of 14 cases $(25 \mu \mathrm{A}$ : $0.7 \pm 0.3 \mathrm{mV} ; 400 \mu \mathrm{A}$ : $6.3 \pm 1.2 \mathrm{mV}$; one-way ANOVA, $p=0.0008$; data not shown). DNQX $(20 \mu \mathrm{M})$ completely blocked EPSPs in 6 of 6 cells tested (Fig. $4 E$ ), confirming that they were mediated by glutamate release. Finally, repeated fornix stimulations given at $5 \mathrm{~Hz}$ could reliably evoke rhythmic EPSPs in 5 of 7 cells, leading to spikes that faithfully followed each stimulus in one cell (Fig. $4 F$ ). These results demonstrate that electrical stimulation of the septohippocampal pathway can induce glutamatergic postsynaptic responses in a significant proportion $(35 / 62 ; 56 \%)$ of CA3 pyramidal cells.

Importantly, the timing of EPSPs versus IPSPs evoked by the fornix stimulation was different. To measure the onset latency of the two types of responses in CA3 pyramidal cells, fornix stimulation was given while the cells were held at $-80 \mathrm{mV}$ (a membrane potential where NMDA receptor-mediated currents are null). In those cells that exhibited both EPSP and IPSP, bicuculline was applied to isolate the EPSP, and the EPSP component was subtracted from the control trace to obtain the IPSP mediated by $\mathrm{GABA}_{\mathrm{A}}$ receptors (Fig. 4C). When EPSPs, subtracted IPSPs, and actual IPSPs (responses recorded from cells that showed only IPSPs upon fornix stimulation) were compared, the mean onset latency of EPSPs was significantly shorter than that of subtracted IPSPs or actual IPSPs (13.3 $\pm 1.0,22.2 \pm 1.8$, and $33.1 \pm 5.3 \mathrm{~ms}$, respectively; $p<0.0001$ ) (see Fig. $4 D$ ). The peak amplitudes of EPSPs, subtracted IPSPs, and actual IPSPs evoked by a $400 \mu$ A stimulus were $6.1 \pm 1.1,4.8 \pm 0.5$, and $6.5 \pm 0.7 \mathrm{mV}$, respectively.

It may be argued that electrical stimulation of the fornix not only activates septohippocampal pathway but also hippocamposeptal fibers. Pyramidal cells of the hippocampus send important projections to the lateral septum (Linke et al., 1995), and the antidromic activation of the axons of CA3 pyramidal cells may partly contribute to the postsynaptic glutamatergic responses reported here (i.e., indirectly through CA3 recurrent collateral synapses). Although we believe that this is unlikely because antidromic activation was never observed in 62 CA3 pyramidal cells recorded, we decided to use local chemical activation of MS-DBB neurons to elicit monosynaptic responses in CA3 pyramidal cells. To do this, we used a puffer pipette to infuse small amounts of NMDA directly in the MS$\mathrm{DBB}$ in the septohippocampal preparation and concomitantly recorded from CA3 pyramidal cells (Fig. 5Ai). First, we tried the NMDA puffs and recorded from VGLUT2-eGFP- $(+)$ MS-DBB neurons close to the puffer pipette to test whether glutamatergic neurons are stimulated by NMDA. We confirmed that local NMDA applications ( $200 \mu \mathrm{M}, 100 \mathrm{~ms}$ duration) led to prolonged depolarizations and firing of multiple action potentials in 7 of 12 glutamatergic MS-DBB cells tested (Fig. 5Aii).

Of 48 CA3 pyramidal cells recorded, we found that applying NMDA locally in the MS-DBB ( 3 puffs given at interpuff intervals of $200 \mathrm{~ms}$ ) clearly evoked time-locked EPSPs in 6 cells. The remaining 42 CA3 pyramidal cells showed no apparent response. Figure $5 B$ demonstrates an example where the EPSPs occurred $\sim 300 \mathrm{~ms}$ after the onset of the first NMDA puff during four consecutive trials. When the same cell was held at $-60 \mathrm{mV}$, the EPSPs triggered the cell to fire action potentials, indicating that the response was excitatory. The EPSPs were resistant to bicucul-
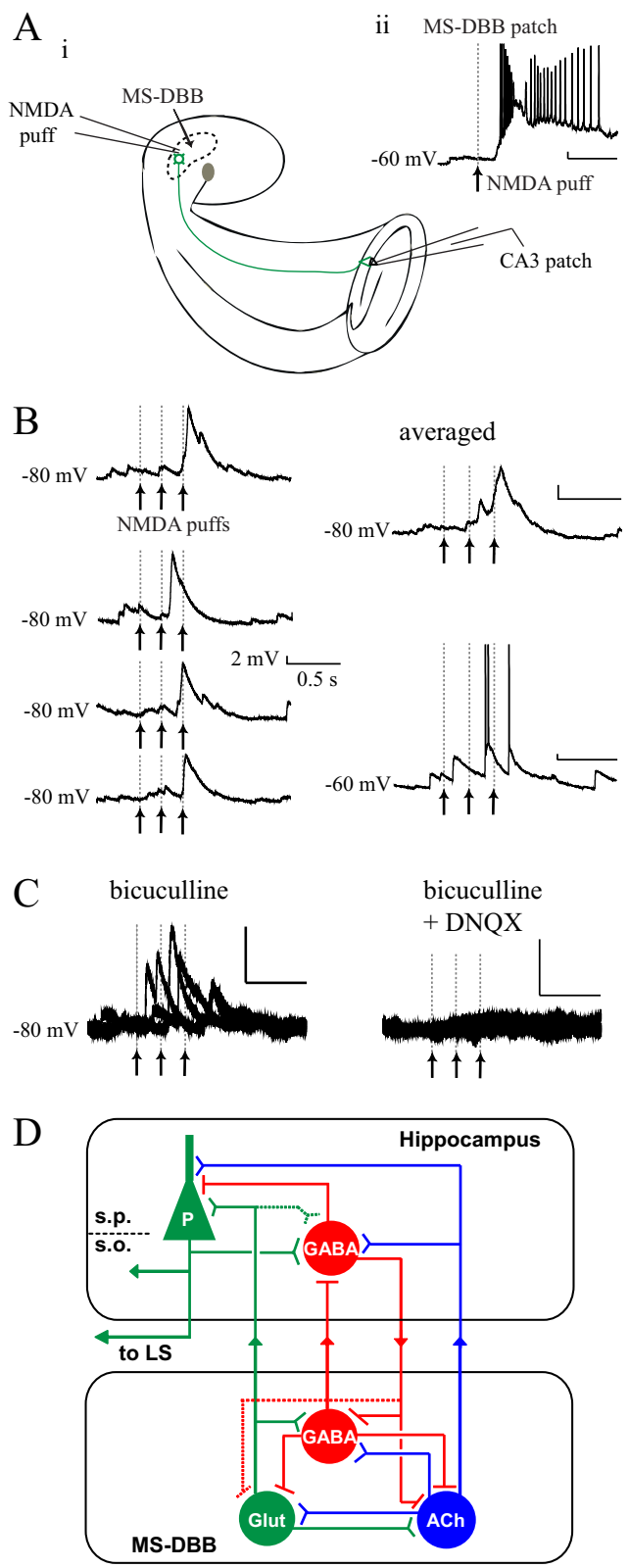

Figure 5. Local NMDA microinfusions to the MS-DBB triggered glutamatergic responses in CA3 pyramidal cells. $\boldsymbol{A i}$, In the septohippocampal preparation, MS-DBB neurons were locally activated by infusing small amounts of NMDA directly into the MS-DBB area using a puffer pipette while recording from CA3 pyramidal cells. Aii, A single NMDA application (200 $\mu \mathrm{m}, 100$ ms) robustly depolarized a nearby VGLUT2-eGFP- $(+)$ MS-DBB neuron. $B$, CA3 pyramidal cells responded to NMDA injections in the MS-DBB with EPSPs that were clearly time-locked to the stimuli (left: four consecutive trials at $-80 \mathrm{mV}$; right top: averaged trace at $-80 \mathrm{mV}$; right bottom: a raw trace at $-60 \mathrm{mV}$ ). C, The EPSPs were abolished by $20 \mu \mathrm{m}$ DNQX, indicating that the response was mediated by glutamate. $D, A$ new model of the septohippocampal network: a subset of glutamatergic MS-DBB neurons may serve as intrinsic rhythm generators that can contribute a rhythmic excitatory drive to the local septal network as well as to the hippocampus. In the model, solid lines represent physiologically confirmed pathways and dotted lines indicate pathways that remain to be demonstrated. ACh, Acetylcholine; Glut, Glutamate; LS, lateral septum; S.P., stratum pyramidale; S.O., stratum oriens; P, pyramidal cell.

line ( $5 \mu \mathrm{M} ; 4 / 4$ cells tested) but abolished by DNQX $(20 \mu \mathrm{M} ; 2 / 2$ cases) (Fig. $5 C$ ), confirming that they were indeed mediated by glutamate release. The mean onset latency of the EPSPs relative to the onset of the first NMDA puff was $265.4 \pm 48.9 \mathrm{~ms}$, and the mean peak amplitude at $-80 \mathrm{mV}$ was $4.4 \pm 0.6 \mathrm{mV}$ (6 cells). These results indicate that local activation of MS-DBB cells gives 
rise to glutamatergic postsynaptic responses in CA3 pyramidal cells and provide the first electrophysiological evidence that the glutamatergic septohippocampal pathway is functional.

\section{Discussion}

Glutamatergic neurons of the MS-DBB are still often overlooked in most models of septohippocampal interactions. This stems in part from the lack of evidence that these glutamatergic neurons have any role in the modulation of hippocampal activity, and no study has yet fully characterized their electrophysiological properties. The present study demonstrates for the first time that (1) some glutamatergic MS-DBB neurons possess fast-firing properties identical to fast-firing GABAergic MS-DBB neurons and exhibit rhythmic spontaneous firing at theta frequencies, and (2) glutamatergic MS-DBB neurons provide excitatory synaptic input to CA3 pyramidal cells. These results provide new evidence that the third element in the septohippocampal pathway, the glutamatergic MS-DBB neurons, can robustly modulate hippocampal activity and suggest that they may contribute to hippocampal theta oscillations and play a potentially important role in memory.

\section{VGLUT2-eGFP-(+) MS-DBB neurons release glutamate and are electrophysiologically heterogeneous}

Our autaptic culture results demonstrate that the only neurotransmitter released by VGLUT2-expressing MS-DBB neurons is glutamate, confirming the functional neurotransmitter phenotype of VGLUT2-eGFP- $(+)$ neurons. This is important with respect to recent studies that used the same transgenic mouse line to visualize glutamatergic neurons of the MS-DBB (Dumalska et al., 2008; Henderson et al., 2010). In addition, we also show that GAD65-eGFP-(+) MS-DBB neurons only release GABA. This is unlike cholinergic MS-DBB neurons that have been shown to corelease GABA or glutamate under certain conditions (Allen et al., 2006; Huh et al., 2008).

It has been generally assumed that in the MS-DBB, slow-firing neurons are cholinergic while other firing patterns such as fast firing and burst firing correspond to GABAergic neurons (Jones et al., 1999; Henderson et al., 2001). Here, we demonstrate that glutamatergic MS-DBB neurons as a population exhibit a highly heterogeneous set of firing patterns with a significant proportion (47\%) displaying fast-firing properties that are virtually indistinguishable from fast-firing GABAergic cells. Our finding of fastfiring glutamatergic MS-DBB neurons is supported by recent evidence that some VGLUT2-eGFP-(+) MS-DBB neurons express Kv3.1b (Henderson et al., 2010), a delayed rectifier channel involved in rapid spike repolarization common to fast-spiking CNS neurons (Rudy and McBain, 2001). We also demonstrate that in response to hyperpolarizing currents, an important subset (39\%) of fast-firing glutamatergic MS-DBB neurons exhibit prominent depolarizing sag mediated by $\mathrm{I}_{\mathrm{h}}$ with amplitude, kinetics, and pharmacological profile similar to those of GABAergic MS-DBB neurons. Given previous reports that blocking $\mathrm{I}_{\mathrm{h}}$ in the MS-DBB substantially decreases the frequency of hippocampal theta rhythm in vivo (Kocsis and $\mathrm{Li}, 2004$ ), our results suggest that $\mathrm{I}_{\mathrm{h}}$-expressing GABAergic and glutamatergic MS-DBB neurons may both participate in hippocampal theta oscillations.

Importantly, we found that some electrophysiological characteristics could be used to distinguish between glutamatergic and GABAergic MS-DBB neurons. Namely, the only firing pattern unique to glutamatergic neurons was cluster firing interspersed with subthreshold membrane oscillations, in line with Sotty et al. (2003) who detected cluster firing only in MS-DBB neurons solely expressing glutamatergic markers (VGLUT transcripts). Some glutamatergic neurons exhibited burst firing that is distinct from the burst firing observed in GABAergic cells, similar to the two types of burst firing reported by Henderson et al. (2001). Subsets of glutamatergic and GABAergic neurons displayed the slow-firing pattern with broad action potentials similar to cholinergic MS-DBB neurons (Gorelova and Reiner, 1996; Sotty et al., 2003), but a direct comparison with cholinergic neurons was not done here. Together, cluster firing may be used as an electrophysiological marker for glutamatergic neurons in the MS-DBB, whereas fast- and burst-firing patterns alone may not be used as reliable indicators for glutamatergic or GABAergic MS-DBB neurons.

\section{Glutamatergic MS-DBB neurons can spontaneously fire rhythmically at theta frequencies}

The MS-DBB has long been thought of as an important rhythm generator for the hippocampus (Buzsáki, 2002) because in vivo many MS-DBB cells fire rhythmically phase locked to hippocampal oscillations (Stewart and Fox, 1989), and lesions of the MSDBB cause large reductions in the power of hippocampal theta (Green and Arduini, 1954; Lee et al., 1994; Yoder and Pang, 2005). These lines of evidence have been taken to indicate that rhythmic MS-DBB neurons are critically involved in hippocampal theta rhythm. GABAergic MS-DBB neurons have been identified to account for some of the rhythmic cells in vivo (Borhegyi et al., 2004; Simon et al., 2006), but it remains unknown whether glutamatergic MS-DBB neurons also fire rhythmically during hippocampal theta. It has been reported that in vivo some noncholinergic, non-GABAergic MS-DBB neurons fire tonically or in clusters during theta (Simon et al., 2006). It also remains to be demonstrated whether the rhythmic firing is due to intrinsic membrane properties, extrinsic factors, or a combination of both. Earlier reports using extracellular and sharp electrodes have noted that some spontaneously active MS-DBB neurons appear to be rhythmic (Segal, 1986; Morris et al., 1999; Henderson et al., 2001), but the neurochemical identity of these neurons and quantification of their rhythmicity have not been explored. Our analysis revealed that subsets of both glutamatergic and GABAergic MS-DBB neurons show highly rhythmic spontaneous firing in the theta range that is not driven by extrinsic rhythmic inputs, suggesting that some MS-DBB neurons possess intrinsic rhythmic properties. Our results are the first to demonstrate in vitro that some glutamatergic and GABAergic MS-DBB neurons may have the intrinsic capacity to be theta rhythm generators.

\section{Functional glutamatergic septohippocampal projection}

Although previous anatomical studies have estimated that glutamatergic MS-DBB neurons account for $4-23 \%$ of the septohippocampal projection (Colom et al., 2005; Henderson et al., 2010), no evidence existed until now as to whether glutamatergic MSDBB neurons can modulate hippocampal neurons. It may be that the glutamatergic septohippocampal fibers are relatively few in number, but they each innervate the target cells heavily, having a large functional impact. In line with this idea, a recent preliminary study showed numerous VGLUT2-positive septohippocampal puncta in close apposition with the soma and proximal dendrites of CA1 and CA3 pyramidal cells and interneurons (L.V. Colom, personal communication). Using fornix stimulation and direct activation of MS-DBB neurons, we demonstrate that glutamatergic MS-DBB neurons provide excitatory synaptic input to CA3 pyramidal cells. Electrical stimulation of septohippocampal fibers evoked glutamate-mediated EPSPs in $56 \%$ of the CA3 
pyramidal cells tested. Fornix stimulation, however, is subject to nonspecific effects because it may also antidromically activate CA3 pyramidal cells or activate other glutamatergic fibers innervating the hippocampus through the fornix originating from the supramammillary area or the nucleus reuniens (Leranth and Kiss, 1996; Nitsch and Leranth, 1996). To circumvent this issue, we used NMDA microinfusions into the MS-DBB to directly stimulate glutamatergic MS-DBB neurons and demonstrated monosynaptic AMPA receptor-mediated glutamatergic responses in 13\% of the CA3 pyramidal cells tested. The lower probability of detecting a response using chemical activation may be because local NMDA puffs affect only a small number of MS-DBB neurons located very close to the puff pipette and/or because NMDA may activate only a proportion of glutamatergic neurons.

It remains to be determined whether hippocampal interneurons receive glutamatergic septal input. We found that fornix stimulation induced late-onset IPSPs in almost all (45/46) CA3 pyramidal cells examined. The IPSPs appeared with relatively long delays and a large variability in the onset suggesting that they probably reflect a multisynaptic response. Considering that pyramidal cells do not appear to receive a direct GABAergic input from MS-DBB neurons (Freund and Antal, 1988), it is likely that the IPSPs recorded in pyramidal cells are a result of the activation of GABAergic interneurons via glutamatergic septal input. Recordings of interneurons during direct stimulation of MS-DBB neurons will be required to resolve this issue.

Finally, our results suggest a unique role of the glutamatergic MS-DBB neurons in septohippocampal network. Cholinergic MS-DBB neurons may provide long-lasting excitation to both pyramidal cells and interneurons, while GABAergic MS-DBB neurons transmit short rhythmic inhibition solely to GABAergic interneurons (Toth et al., 1997). We propose that glutamatergic MS-DBB neurons induce fast depolarizations that can trigger spiking in hippocampal pyramidal cells. If these depolarizations are rhythmic, they could provide a powerful synchronizing input and potentially contribute to hippocampal theta oscillations. Previous results show that glutamatergic MS-DBB neurons can rhythmically excite neighboring neurons within the MS-DBB (Manseau et al., 2005). Thus, the role of the glutamatergic neurons may be to contribute a rhythmic excitatory drive to the local network as well as to the hippocampus (Fig. 5D). An approach involving selective inhibition or elimination of glutamatergic MS-DBB neurons will be necessary to determine the exact contribution of these neurons to hippocampal theta and related functions.

\section{A new model of septohippocampal interactions}

The MS-DBB has been classically viewed as the hippocampal theta rhythm generator (Stewart and Fox, 1989; Buzsáki, 2002). However, the role of the MS-DBB in hippocampal theta oscillations must be revised in light of our recent discovery that the hippocampus itself can generate a theta-frequency rhythm independent from the MS-DBB (Goutagny et al., 2009). We therefore suggest that the MS-DBB is one of several extrinsic rhythm generators that amplify and regulate intrinsic theta generators within the hippocampus. Hence, the hippocampal theta rhythm recorded in vivo may be a product of several interacting intrinsic and extrinsic theta generators working in concert. It remains to be elucidated what role glutamatergic, GABAergic, and cholinergic MS-DBB neurons play in these interactions, but a greater understanding of these matters will bring new insights into the mechanisms underlying functions such as spatial learning and memory.

\section{References}

Allen TG, Abogadie FC, Brown DA (2006) Simultaneous release of glutamate and acetylcholine from single magnocellular "cholinergic" basal forebrain neurons. J Neurosci 26:1588-1595.

Borhegyi Z, Varga V, Szilágyi N, Fabo D, Freund TF (2004) Phase segregation of medial septal GABAergic neurons during hippocampal theta activity. J Neurosci 24:8470-8479.

Bourque MJ, Trudeau LE (2000) GDNF enhances the synaptic efficacy of dopaminergic neurons in culture. Eur J Neurosci 12:3172-3180.

Buzsáki G (2002) Theta oscillations in the hippocampus. Neuron 33:325-340.

Cole AE, Nicoll RA (1983) Acetylcholine mediates a slow synaptic potential in hippocampal pyramidal cells. Science 221:1299-1301.

Colom LV, Castaneda MT, Reyna T, Hernandez S, Garrido-Sanabria E (2005) Characterization of medial septal glutamatergic neurons and their projection to the hippocampus. Synapse 58:151-164.

Danik M, Cassoly E, Manseau F, Sotty F, Mouginot D, Williams S (2005) Frequent coexpression of the vesicular glutamate transporter 1 and 2 genes, as well as coexpression with genes for choline acetyltransferase or glutamic acid decarboxylase in neurons of rat brain. J Neurosci Res 81:506-521.

Dumalska I, Wu M, Morozova E, Liu R, van den Pol A, Alreja M (2008) Excitatory effects of the puberty-initiating peptide kisspeptin and group I metabotropic glutamate receptor agonists differentiate two distinct subpopulations of gonadotropin-releasing hormone neurons. J Neurosci 28:8003-8013.

Fremeau RT Jr, Troyer MD, Pahner I, Nygaard GO, Tran CH, Reimer RJ, Bellocchio EE, Fortin D, Storm-Mathisen J, Edwards RH (2001) The expression of vesicular glutamate transporters defines two classes of excitatory synapse. Neuron 31:247-260.

Freund TF, Antal M (1988) GABA-containing neurons in the septum control inhibitory interneurons in the hippocampus. Nature 336:170-173.

Gong S, Zheng C, Doughty ML, Losos K, Didkovsky N, Schambra UB, Nowak NJ, Joyner A, Leblanc G, Hatten ME, Heintz N (2003) A gene expression atlas of the central nervous system based on bacterial artificial chromosomes. Nature 425:917-925.

Gorelova N, Reiner PB (1996) Role of the afterhyperpolarization in control of discharge properties of septal cholinergic neurons in vitro. J Neurophysiol 75:695-706.

Goutagny R, Manseau F, Jackson J, Danik M, Williams S (2008) In vitro activation of the medial septum-diagonal band complex generates atropine-sensitive and atropine-resistant hippocampal theta rhythm: an investigation using a complete septohippocampal preparation. Hippocampus 18:531-535.

Goutagny R, Jackson J, Williams S (2009) Self-generated theta oscillations in the hippocampus. Nat Neurosci 12:1491-1493.

Green JD, Arduini AA (1954) Hippocampal electrical activity in arousal. J Neurophysiol 17:533-557.

Griffith WH (1988) Membrane properties of cell types within guinea pig basal forebrain nuclei in vitro. J Neurophysiol 59:1590-1612.

Griffith WH, Matthews RT (1986) Electrophysiology of AChE-positive neurons in basal forebrain slices. Neurosci Lett 71:169-174.

Hajszan T, Alreja M, Leranth C (2004) Intrinsic vesicular glutamate transporter 2-immunoreactive input to septohippocampal parvalbumincontaining neurons: novel glutamatergic local circuit cells. Hippocampus 14:499-509.

Henderson Z, Morris NP, Grimwood P, Fiddler G, Yang HW, Appenteng K (2001) Morphology of local axon collaterals of electrophysiologically characterised neurons in the rat medial septal/ diagonal band complex. J Comp Neurol 430:410-432.

Henderson Z, Lu CB, Janzsó G, Matto N, McKinley CE, Yanagawa Y, Halasy K (2010) Distribution and role of Kv3.1b in neurons in the medial septum diagonal band complex. Neuroscience 166:952-969.

Huh CY, Danik M, Manseau F, Trudeau LE, Williams S (2008) Chronic exposure to nerve growth factor increases acetylcholine and glutamate release from cholinergic neurons of the rat medial septum and diagonal band of Broca via mechanisms mediated by p75NTR. J Neurosci 28:1404-1409.

Jones GA, Norris SK, Henderson Z (1999) Conduction velocities and membrane properties of different classes of rat septohippocampal neurons recorded in vitro. J Physiol 517:867-877.

Knapp JA, Morris NP, Henderson Z, Matthews RT (2000) Electrophysiological characteristics of non-bursting, glutamate decarboxylase messen- 
ger RNA-positive neurons of the medial septum/diagonal band nuclei of guinea-pig and rat. Neuroscience 98:661-668.

Kocsis B, Li S (2004) In vivo contribution of h-channels in the septal pacemaker to theta rhythm generation. Eur J Neurosci 20:2149-2158.

Lee MG, Chrobak JJ, Sik A, Wiley RG, Buzsáki G (1994) Hippocampal theta activity following selective lesion of the septal cholinergic system. Neuroscience 62:1033-1047.

Leranth C, Kiss J (1996) A population of supramammillary area calretinin neurons terminating on medial septal area cholinergic and lateral septal area calbindin-containing cells are aspartate/glutamatergic. J Neurosci 16:7699-7710.

Lin W, McKinney K, Liu L, Lakhlani S, Jennes L (2003) Distribution of vesicular glutamate transporter-2 messenger ribonucleic acid and protein in the septum-hypothalamus of the rat. Endocrinology 144:662-670.

Linke R, Pabst T, Frotscher M (1995) Development of the hippocamposeptal projection in the rat. J Comp Neurol 351:602-616.

Manseau F, Danik M, Williams S (2005) A functional glutamatergic neurone network in the medial septum and diagonal band area. J Physiol $566: 865-884$.

Manseau F, Goutagny R, Danik M, Williams S (2008) The hippocamposeptal pathway generates rhythmic firing of GABAergic neurons in the medial septum and diagonal bands: an investigation using a complete septohippocampal preparation in vitro. J Neurosci 28:4096-4107.

Markram H, Segal M (1990) Electrophysiological characteristics of cholinergic and non-cholinergic neurons in the rat medial septum-diagonal band complex. Brain Res 513:171-174.

Morris NP, Harris SJ, Henderson Z (1999) Parvalbumin-immunoreactive, fast-spiking neurons in the medial septum/diagonal band complex of the rat: intracellular recordings in vitro. Neuroscience 92:589-600.

Morris NP, Fyffe RE, Robertson B (2004) Characterisation of hyperpolarization- activated currents $(\mathrm{I}(\mathrm{h}))$ in the medial septum/diagonal band complex in the mouse. Brain Res 1006:74-86.

Nitsch R, Leranth C (1996) GABAergic neurons in the rat dentate gyrus are innervated by subcortical calretinin-containing afferents. J Comp Neurol 364:425-438.

Royer S, Sirota A, Patel J, Buzsáki G (2010) Distinct representations and theta dynamics in dorsal and ventral hippocampus. J Neurosci 30:1777-1787.

Rudy B, McBain CJ (2001) Kv3 channels: voltage-gated K+ channels designed for high-frequency repetitive firing. Trends Neurosci 24:517-526.

Segal M (1986) Properties of rat medial septal neurones recorded in vitro. J Physiol 379:309-330.

Simon AP, Poindessous-Jazat F, Dutar P, Epelbaum J, Bassant MH (2006) Firing properties of anatomically identified neurons in the medial septum of anesthetized and unanesthetized restrained rats. J Neurosci 26:9038-9046.

Sotty F, Danik M, Manseau F, Laplante F, Quirion R, Williams S (2003) Distinct electrophysiological properties of glutamatergic, cholinergic and GABAergic rat septohippocampal neurons: novel implications for hippocampal rhythmicity. J Physiol 551:927-943.

Stewart M, Fox SE (1989) Two populations of rhythmically bursting neurons in rat medial septum are revealed by atropine. J Neurophysiol 61:982-993.

Tóth K, Freund TF, Miles R (1997) Disinhibition of rat hippocampal pyramidal cells by GABAergic afferents from the septum. J Physiol 500:463-474.

Widmer H, Ferrigan L, Davies CH, Cobb SR (2006) Evoked slow muscarinic acetylcholinergic synaptic potentials in rat hippocampal interneurons. Hippocampus 16:617-628.

Winson J (1978) Loss of hippocampal theta rhythm results in spatial memory deficit in the rat. Science 201:160-163.

Yoder RM, Pang KC (2005) Involvement of GABAergic and cholinergic medial septal neurons in hippocampal theta rhythm. Hippocampus 15:381-392. 